\title{
Electrochemical stability of the polymer-derived nitrogen-doped carbon: an elusive goal?
}

\author{
Kun Cong • Mariusz Radtke $\cdot$ Steffi Stumpf • \\ Bernd Schröter • Duncan G. G. McMillan • \\ Markus Rettenmayr • Anna Ignaszak
}

Received: 14 October 2014/Accepted: 30 January 2015/Published online: 4 March 2015

(c) The Author(s) 2015. This article is published with open access at Springerlink.com

\begin{abstract}
Nitrogen-doped carbon is a promising metalfree catalyst for oxygen reduction reaction in fuel cells and metal-air batteries. However, its practical application necessitates a significant cost reduction, which can be achieved in part by using new synthetic methods and improvement of catalytic activity by increasing the density of redox active centers. This can be modulated by using polymer as the carbon and nitrogen sources. Although, superior catalytic activity of such $\mathrm{N}$-doped $\mathrm{C}$ has been investigated in details, the electrochemical long-term stability of polymer-derived doped-carbon is still unclear. Herein, in this study we generated N-doped carbon from the most recommended polymer that is comparable to the state-of-the-art materials with porosity as high as
\end{abstract}

Electronic supplementary material The online version of this article (doi:10.1007/s40243-015-0046-9) contains supplementary material, which is available to authorized users.

K. Cong $\cdot$ M. Radtke $\cdot$ A. Ignaszak $(\bowtie)$

Institute of Organic and Macromolecular Chemistry, Friedrich-

Schiller University, Lessingstrasse 12, 07743 Jena, Germany

e-mail: anna.ignaszak@uni-jena.de

\section{S. Stumpf}

Jena Center of Soft Mater (JCSM), Friedrich-Schiller University, Philosophenweg 7, 07743 Jena, Germany

B. Schröter

Institute of Solid State Physics, Friedrich-Schiller University, Philosophenweg 7, 07743 Jena, Germany

\section{G. G. McMillan}

University Hospital Jena, Friedrich-Schiller University, Bachstrasse 18, 07743 Jena, Germany

\section{Rettenmayr}

Institute of Metallic Materials, Friedrich-Schiller University, Löbdergaben 32, 07743 Jena, Germany
$2,086 \mathrm{~m}^{2} \mathrm{~g}^{-1}$ and a nitrogen doping level of 3-4 at.\%, of which $56 \%$ is pyrrolic $\mathrm{N}, 36.1 \%$ pyridinic and $\sim 8 \%$ graphitic. The electrochemical characterization shows that $\mathrm{N}$-doped carbon is catalytic toward oxygen reduction in an alkaline electrolyte via a favorable four-electron process, however, not stable under long-term potential scanning. The irreversible electrochemical oxidation of this material is associated with the presence of a significant content or pyrrolic and pyridinic $\mathrm{N}$ close to the edge of the carbon network originating from the polypyrrole precursor. These structures are less stable under operating electrochemical potential. The role of polypyrrole as the precursor of $\mathrm{N}$-doped carbons has to be carefully revised since it supplies sufficient number of catalytic sites, but also generates unstable functionalities on the carbon surface.

Keywords Stability $\cdot$ Electrocatalyst $\cdot$ Nitrogen-doped carbon $\cdot$ Surface functionality

\section{Introduction}

Porous doped carbons are prosperous materials due to valuable features such as relatively low production cost, high electrical conductivity, chemical and thermal stabilities, to name a few of the reasons for their becoming attractive candidates in a wide range of applications [1]. Specifically, nanostructured doped carbons have been extensively used as electrodes, electrocatalysts or catalyst supports in energy storage and conversion devices [2-4]. Among these potential applications, a great deal of research has been devoted to the use of porous carbons as catalysts in fuel cell technology [5]. Cheaper and easily available electrocatalysts for oxygen reduction reaction (ORR) based on nitrogen-doped carbon (NDC) are great 
alternatives to the noble-metal $\mathrm{Pt} / \mathrm{C}$ system with already proven higher activity and stronger resistance against poisoning effects when comparing to the platinum [6]. This remarkable property of nitrogen-doped carbon stems from its unique electronic structure compared to bare carbon. Since nitrogen is considered as n-type carbon dopant, it introduces an electronically disordered carbon structure by donating electrons to carbon, consequently. The local centers with different electron density on the catalyst surface attract and stabilize the absorbed $\mathrm{O}_{2}$, resulting in superior catalytic activity toward electrochemical oxygen reduction [7].

Generally, there are two main approaches to synthesize $\mathrm{N}$-doped carbon. First is a post-synthesis doping of carbon in the presence of nitrogen source, with the most frequent a high-temperature annealing of carbon in the flow of gaseous ammonia [8-10]. Although this method is efficient with respect to the doping level, relatively harsh conditions used during ammonia treatment generate a serious safety risk, requiring special corrosion-resistant equipment and a storage-controlling system. For this reason, extensive studies are prompted to search for alternative methods. One of the most promising is to adapt nitrogen-rich carbon precursors, e.g. organic compounds [11], such as polypyrrole (PPy) [12], polyaniline (PANI) [2] and polyacrylonitrile [13]. In summary, this method provides a high surface area product with homogenous morphology due to low conversion (polymer-to-carbon) temperature, allowing to control better the final properties, such as the surface concentration of nitrogen, and the way it is incorporated in the carbon structure (e.g., as pyrrolic, graphitic, pyridinic or quaternary N-C states) [14]. Although the effect of nitrogen doping level (i.e., an established optimum at $2-15$ at.\% of $\mathrm{N}$ ) on the catalytic activity toward oxygen reduction has been well described, there are discrepancies with regards to the long-term electrochemical stability of these compounds $[15,16]$. In general, we observe that all $\mathrm{N}$-doped carbons consisting of graphitized carbon including carbon nanotubes [17] or graphene [18] show superior electrochemical stability under extensive potential cyclic in alkaline media, owing to the presence of graphitic basal plane structure that is resistant to irreversible chemical or electrochemical oxidation [19]. The greater extent of graphitization stabilizes the carbon against oxidation in comparison to the amorphous phase. In contrary, there is a lack of information with regard to the electrochemical durability of the polymer-derived $\mathrm{N}$-doped carbons with a polymer as the only sources of carbon and nitrogen. Current literature supports the claim that an ultra-high surface area is achievable, resulting in excellent catalytic activity [20, 21], however the electrochemical stability of this type of metal-free catalyst over a commercially useful potential range is unclear. For example, some groups observed instability of the polymer-derived $\mathrm{N}$-doped carbon and associated it with chemical incompatibility of a binder used to prepare the electrode [20]. Another group claims the electrochemical stability, but the degradation conditions applied in their work are not relevant to the operating potential window expected for the ORR catalysts [21]. This motivates us to critically assess the long-term electrochemical durability of $\mathrm{N}$-doped carbon made from the polymer as only carbon and nitrogen precursor. In this work we generate a model compound, whose properties are comparable to the current state-of-the-art ultra-porous $\mathrm{N}$-doped carbon with the $\mathrm{N}$-doping level in the range (2-15 at.\%). By employing polypyrrole, the most frequently used and promising precursor for $\mathrm{N}$-doped $\mathrm{C}$, we ensure optimum catalytic activity toward electrochemical oxygen reduction. Here we adapt a template-assisted synthesis of the polymer precursor and a robust post chemical and thermal annealing in order to achieve the representative product. This will be analyzed in detail with regard to the chemical structure, electrochemical stability, and electrochemical performance. The stability of this model system will be studied using voltammetry and impedance spectroscopy correlated with the surface elemental composition and the structure of the both the fresh and degraded compound.

\section{Experimental}

\section{Materials}

All reagents and solvents were purchased from SigmaAldrich and used without further purification unless described. Pyrrole (Py) was distilled and stored under argon. $\mathrm{FeCl}_{3}$ was used as an oxidizing agent for the polymerization. Nafion monomer was purchased as $5 \mathrm{wt} \%$ solution in mixture of alcohols. Silica spheres of $0.15-0.55 \mu \mathrm{m}$ diameter were received from Polysciences $\mathrm{GmbH}$ as $5.0 \mathrm{wt} \%$ aqueous suspensions. Nitric acids $\left(\mathrm{HNO}_{3}\right)$ and potassium hydroxide $(\mathrm{KOH})$ were used for washing and to prepare electrolyte, respectively. All solutions were prepared from deionized water of resistivity $18 \mathrm{M} \Omega$ and degassed prior measurement with high purity argon $(99.999 \%)$.

\section{Methods}

The product identification was performed using a solid state FTIR spectrophotometer for the chemical composition (IR Affinity-1 Shimadzu, a pure $\mathrm{KBr}$ tablet was used as a blank for the background subtraction). Thermal analysis (STA 449F1 Jupiter, Netzsch) was carried out in Ar with heating/cooling step of $5{ }^{\circ} \mathrm{C} \mathrm{min}{ }^{-1}$ to determine the optimum temperature of the polymer-to-carbon conversion 
(Fig. S1). The surface area, pore size, and pore volume were determined with a Quantachrome Autosorb analyzer (Quantachrome Corporation). Adsorption-desorption isotherms were recorded at $77 \mathrm{~K}$ using $\mathrm{N}_{2}$ as the adsorbate. The adsorption data was analyzed using the Autosorb software version 1.16 based on the BET isotherm and the BJH method allowing estimating the pore size distribution and a cumulative pore volume. X-ray photoelectron spectroscopy (XPS) measurements were performed on Leybold Max 200 spectrometer using Mg KR radiation $(1,253.6 \mathrm{eV})$ operated at $200 \mathrm{~W}(10 \mathrm{kV}, 20 \mathrm{~mA})$. All data were calibrated with respect to the $\mathrm{C} 1 \mathrm{~s}$ excitation $(284.6 \mathrm{eV})$ to account for charging effects by the electron beam. Prior to individual elemental scans, survey scans were acquired with a $1 \mathrm{eV}$ step to estimate the surface (depth $<10 \mathrm{~nm}$ ) composition. Narrow scans for $\mathrm{C} 1 \mathrm{~s}$ and $\mathrm{N} 1 \mathrm{~s}$ were carried out with $0.2 \mathrm{eV}$ step size, revealing information of the chemical state of each sample. The spectra were fitted and evaluated by XPSPEAK 4.1 software: a mixed GaussianLorentzian function (G:L 85:15) was used for the peak shapes, while the Shirley function was applied to subtract the background. X-ray diffraction (XRD) was performed using Inel $120 \mathrm{CPS}$ instrument with $\mathrm{Cu}-\mathrm{K} \alpha$ radiation in the range of $2 \theta$ from $10^{\circ}$ to $55^{\circ}$. Scanning electron microscopy (SEM) observations were performed using a LEO-1450 VP microscope at $8.0 \mathrm{kV}$.

Electrochemical experiments were carried out using a Princeton Applied Research VersaSTAT MC potentiostat and an electrochemical cell containing platinum counter electrode, $\mathrm{Ag} / \mathrm{AgCl}$ (in saturated $\mathrm{KCl}$ solution) as a reference electrode and $\mathrm{N}$-doped carbon ink casted onto glassy carbon as a working electrode. All potentials are quoted versus $\mathrm{Ag} / \mathrm{AgCl}(+197 \mathrm{mV})$. All electrochemical measurements were carried out in $0.1 \mathrm{M} \mathrm{KOH}$ purged with $\mathrm{N}_{2}$ or $\mathrm{O}_{2}$ for $30 \mathrm{~min}$ prior to experiments. Before casting the glassy carbon disk of $0.5 \mathrm{~cm}$ diameter (PINE Instrument Company, USA) was mechanically polished with $0.05 \mu \mathrm{m}$ $\mathrm{Al}_{2} \mathrm{O}_{3}$ slurry (Cypress Systems, Inc., USA), then rinsed in deionized water, cleaned ultrasonically in ultrapure water for $5 \mathrm{~min}$, followed by rinsing in ultrapure isopropanol and acetone. A standard ink containing $5 \mathrm{mg}$ of $\mathrm{N}$-doped carbon, $1,080 \mu \mathrm{L}$ ethanol and $180 \mu \mathrm{L} 5 \mathrm{wt} \%$ Nafion was sonicated for $30 \mathrm{~min}$, and a $10 \mu \mathrm{L}$ of suspension was cast on glassy carbon disk, and dried in ambient conditions. Various concentrations of Nafion binder were used in order to investigate the mechanical stability of the $\mathrm{N}$-doped carbon electrodes. Cyclic voltammetry $(\mathrm{CV})$ in $\mathrm{O}_{2}$ - and $\mathrm{N}_{2}$ saturated electrolyte was carried out in the potential range from -0.8 to $0.6 \mathrm{~V}$ versus $\mathrm{Ag} / \mathrm{AgCl}$, and a scan rate of $50 \mathrm{mV} \mathrm{s}^{-1}$. The catalytic activity for oxygen reduction was investigated using linear scan voltammetry (LSV) applied to the rotating disk electrode in the potential range from 0.4 to $-1.0 \mathrm{~V}$ with the scan rate of $10 \mathrm{mV} \mathrm{s}^{-1}$ and the rotation speed from 0 to 2,500 $\mathrm{rpm}$ in $\mathrm{O}_{2}$-saturated electrolyte. A long-term stability test was performed by scanning potential at $200 \mathrm{mV} \mathrm{s}^{-1}$ using electrolyte with an $\mathrm{O}_{2}$ blanket (typically 2,000 scans without rotation of the electrode) using CV and LSV voltammograms for the comparison with relevant scans for the fresh electrode.

\section{Results and discussion}

Synthesis of porous N-doped carbon

In a typical synthesis procedure, $2.3 \mathrm{~g}$ oxidant $\mathrm{FeCl}_{3}$ with the ratio of 2.2:1 (oxidant to monomer) was dissolved in $30 \mathrm{ml} \mathrm{H}_{2} \mathrm{O}$ followed by the addition of $3.2 \mathrm{~g}$ of a $10 \%$ silica aqueous suspension. The $\mathrm{FeCl}_{3}$ and $\mathrm{SiO}_{2}$ template mixture was sonicated for $10 \mathrm{~min}$ and then combined with $0.42 \mathrm{~mL}$ of a freshly distilled pyrrole under vigorous stirring. The reaction was carried out for $8 \mathrm{~h}$ until the color of the suspension changed from light yellow to the characteristic dark green associated with polypyrrole formation. The mixture was then filtered, washed with ethanol and water until the filtrate became colorless and dried at $80{ }^{\circ} \mathrm{C}$ for $12 \mathrm{~h}$. The yield of the silica enclosed polypyrrole precursor was around $90 \%$. The chemical activation of polypyrrole prior to thermal treatment was performed by mixing $\left(\mathrm{SiO}_{2}\right.$-PPy) with $3 \mathrm{M} \mathrm{KOH}$ at a weight ratio of 1 to 3. After the solvent evaporation, the mixture was annealed under flow of argon at $675{ }^{\circ} \mathrm{C}$ for $2 \mathrm{~h} . \mathrm{SiO}_{2}$ was leached out in $10 \mathrm{M} \mathrm{KOH}$ solution under a reflux at $110^{\circ} \mathrm{C}$ for $48 \mathrm{~h}$. Finally, the product was $\mathrm{pH}$ neutralized with $1 \mathrm{M}$ $\mathrm{HCl}$, washed with distilled water and dried at $120^{\circ} \mathrm{C}$ overnight.

Structure and chemical composition

For phase identification, an FTIR spectrum was compared with intermediate compound, $\mathrm{SiO}_{2}$-reinforced polypyrrole, and the final product after the carbonization and cleaning (Fig. S2). The characteristic peak of polypyrrole at $751 \mathrm{~cm}^{-1}$ corresponds to the out of plane $\mathrm{C}-\mathrm{H}$ and $\mathrm{N}-\mathrm{H}$ deformations together with a $\mathrm{C}=\mathrm{C}$ stretching vibration at $1,600 \mathrm{~cm}^{-1}$ and $\mathrm{C}-\mathrm{N}$ stretching vibration at $1,340 \mathrm{~cm}^{-1}$ (Fig. S2, red line). A significant difference in FTIR identities between the precursor and the final product occurs within the region from 500 to $1,500 \mathrm{~cm}^{-1}$ wavenumber, where a symmetric and anti-symmetric ring-stretching vibrations of $\mathrm{C}=\mathrm{C}$ bond at 1,540 and $1,454 \mathrm{~cm}^{-1}$, $1,149 \mathrm{~cm}^{-1}$ vibration of pyrrole ring (disappear for $\mathrm{N}$-doped carbon), $1,033 \mathrm{~cm}^{-1}$ in plane $\mathrm{C}-\mathrm{H}$ and $\mathrm{N}-\mathrm{H}$ deformations are present. Also the peak near $1,000 \mathrm{~cm}^{-1}$ attributes to $\mathrm{C}-\mathrm{N}$ stretching is weaker for carbonized material [22]. 


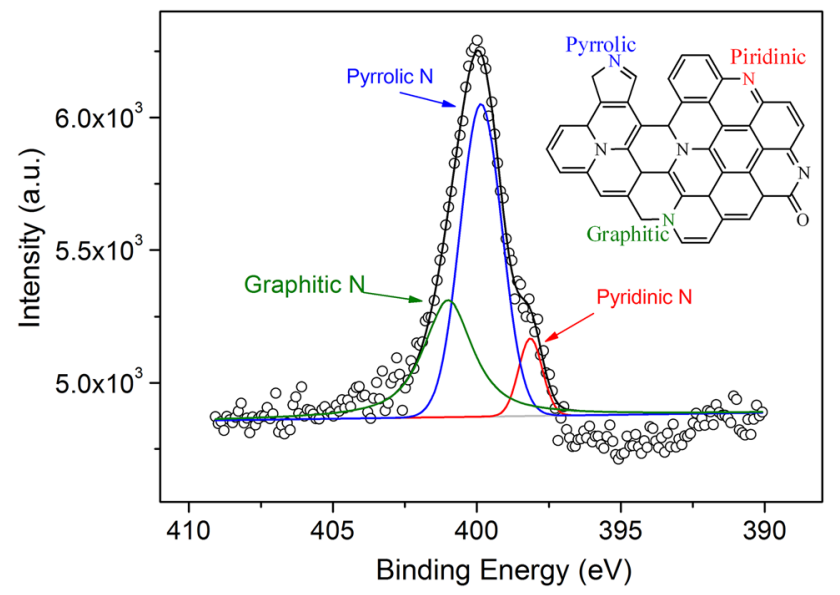

Fig. 1 XPS N1 s narrow scan of N-doped carbon

The nitrogen functional groups are usually in the following molecular structures (chemical states) in N-doped carbons (Fig. 1, insert): pyridinic $\mathrm{N}$ refers to nitrogen atoms at the edge of graphite planes, each of which is bonded to two carbon atoms and donates one $\pi$-electron to the aromatic $\pi$ system; pyrrolic $\mathrm{N}$ refers to nitrogen atoms that are bonded to two carbon atoms and contribute to the $\pi$ system with two $\pi$ electrons; quaternary nitrogen is also called "graphitic nitrogen" or "substituted nitrogen", in which nitrogen atoms are incorporated into the carbon network. The nitrogen state and content is of great significance with regard to the electrochemical activity, however, the influence of nitrogen chemical states on ORR is still yet to be revealed. Some groups claim that the pyridinic $\mathrm{N}$ plays the most important role in ORR activity [23,24], while others consider graphitic nitrogen as the most active centers [25, 26], however it is generally acknowledged that both may equally contribute to the catalytic activity. For the N-doped carbon generated in this study, the total amount of surface nitrogen was 3.05 at.\% with respect to $\mathrm{C}$ and $\mathrm{O}$ content, and is sufficient for the catalytic effect toward ORR [27]. The XPS narrow scan of the $\mathrm{N}$ 1s signal presented in Fig. 1 identifies three types of nitrogen states: graphitic $\mathrm{N}(398.1 \mathrm{eV})$, pyrrolic $\mathrm{N}$ $(399.9 \mathrm{eV})$ and pyridinic $\mathrm{N}(401.0 \mathrm{eV})$ with corresponding fractions of $8.07,56.81$ and $35.12 \%$, respectively. The composition is governed by the structure of polypyrrole precursor that is mostly composed of pyrrolic $\mathrm{N}$.

\section{Morphology of N-doped carbon}

The morphology of N-doped carbon is shown in Fig. 2. SEM micrographs of $\mathrm{SiO}_{2}$-reinforced polypyrrole precursor (Fig. 2a) reveal a uniform, thin-shell polymer coating over oxide templates of various sizes, and the absence of silica-free polypyrrole phase. The following synthesis step ensures a regular porosity of the final product, composed of three-dimensional framework with micron-scale voids
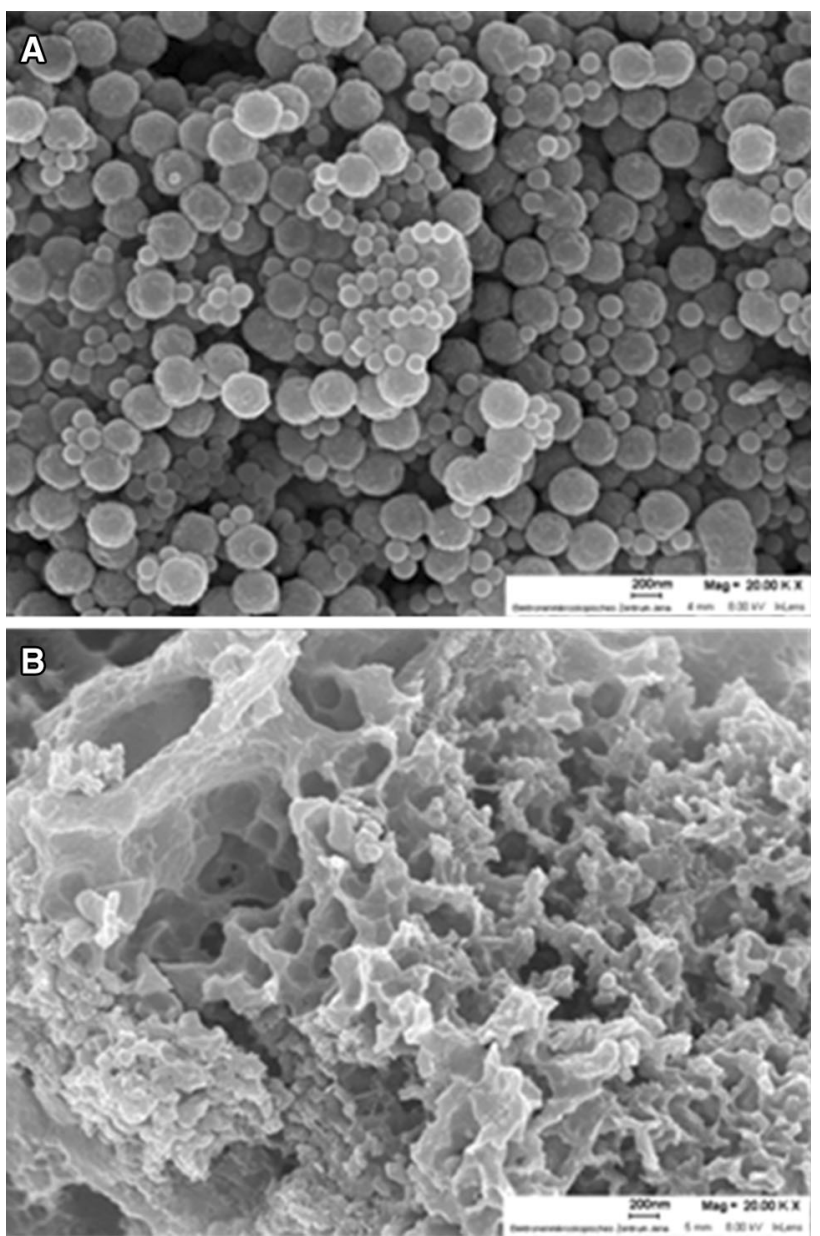

Fig. 2 SEM image of silica reinforced polypyrrole (a) and nitrogendoped carbon after template removal and washing (b)

separated by thin carbon walls (Fig. 2b). The specific surface area and pore structure were measured by $\mathrm{N}_{2}$ adsorption-desorption method at $77 \mathrm{~K}$. The hysteresis loop (Fig. S3) corresponds to type-IV according to IUPAC classification, demonstrating mesoporous range. The multipoint BET surface is very large, $2,086 \mathrm{~m}^{2} \mathrm{~g}^{-1}$, compared to various, currently competing $\mathrm{N}$-doped carbon materials (e.g., 2,370 $\mathrm{m}^{2} \mathrm{~g}^{-1}$ [28]). Regarding the pore size, an average pore diameter calculated by BHJ method was $3 \mathrm{~nm}$, the total pore volume for pores with radius $<42 \mathrm{~nm}$ was $1.1 \mathrm{~cm}^{3} \mathrm{~g}^{-1}$, and for the pore size larger than $100 \mathrm{~nm}$ (based on mathematical model for meso- and macro-pores) the total volume was about $0.096 \mathrm{~cm}^{3} \mathrm{~g}^{-1}$. The original microstructure makes this carbon a competitive alternative for future energy storage and conversion systems.

Validation of electrocatalytic activity for oxygen reduction reaction

The cyclic voltammetry (CV) and rotating disk electrode (RDE) voltammetry were carried out to assess the 
electrocatalytic activity of N-doped carbon towards oxygen reduction. Figure S4a represents cyclic voltammograms recorded under nitrogen (black line) and in a $\mathrm{O}_{2}$-saturated electrolyte (red line); from this comparison we identify the onset potential corresponding to the oxygen reduction; in our study it is $-0.15 \mathrm{~V}$. The large double-layer current is related to the capacitive behavior of the high surface area carbon materials, which makes $\mathrm{N}$-doped carbon also a promising candidate for the capacitor electrodes. Furthermore, Fig. S4b shows linear sweep voltammograms of oxygen reduction process at a different rotation speed of the electrode. A well-pronounced kinetically controlled region up to $-0.42 \mathrm{~V}$ is observed along with a mixed kinetic and mass transfer-controlled step, where current is a function on rotation rate, and in this case, at the potential more negative than $-0.42 \mathrm{~V}$. The corresponding Levich plots [current density as function of square root of rotation speed, $J=f\left(\omega^{-0.5}\right)$; Fig. S4c] at different potentials are in next step used to calculate the number of electrons exchanged in the process $(n)$, according to Eqs. (1) and (2) [29-31]:

$J^{-1}=J_{\mathrm{L}}^{-1}+J_{\mathrm{K}}^{-1}=\left(B \omega^{1 / 2}\right)^{-1}+J_{\mathrm{K}}^{-1}$

$B=0.62 n F C_{\mathrm{o}}\left(D_{\mathrm{o}}\right)^{2 / 3} v^{-1 / 6}$

where $J$ is the measured current density, $J_{\mathrm{k}}$ and $J_{\mathrm{L}}$ are kinetic and diffusion-limiting current densities, $\omega$ is the angular speed of the rotating electrode, $n$ is the overall number of electrons transferred in oxygen reduction process, $F$ is the Faraday constant $\left(F=96,485 \mathrm{C} \mathrm{mol}^{-1}\right), C_{0}$ is the volume concentration of $\mathrm{O}_{2}$ $\left(C_{0}=1.2 \times 10^{-6} \mathrm{~mol} \mathrm{~cm}^{-3}\right), v$ is the kinematic viscosity of the electrolyte $\left(v=0.01 \mathrm{~cm}^{2} \mathrm{~s}^{-1}\right), D_{0}$ is diffusion coefficient of $\mathrm{O}_{2}$ in $0.1 \mathrm{M} \mathrm{KOH}\left(1.9 \times 10^{-5} \mathrm{~cm}^{2} \mathrm{~s}^{-1}\right)$. The calculated number of electron exchange in ORR according to above models is 3.7 , close to theoretically predicated for direct $4-e^{-}$process. This also indicates some influence of an indirect (2- $e^{-}$path) [29-31]. Mixed four- and twoelectron mechanisms are apparently influenced by the wellknown electrochemical oxygen evolution via $2 e^{-}$exchange, while $\mathrm{H}_{2} \mathrm{O}_{2}$ is evolved as an intermediate product on pure carbon $[29,30]$ (in our sample the carbon is predominant phase with only 3.04 at.\% of the surface N). The correlation of ORR mechanism with respect to various nitrogen states on $\mathrm{N}$-doped carbon was discussed in detail by other groups $[32,33]$.

\section{Electrochemical stability}

The electrochemical stability of the N-doped carbon catalyst is still unclear with some groups claiming the $\mathrm{N}$-doped $\mathrm{C}$ is stable thermally and chemically [34], electrochemically in both acidic [35] and alkaline medium [36], and the loss of electrochemical performance under extensive potential cycling is only related to the delamination of the catalyst layer (mechanical instability) [37]. After careful observation, we concluded that most studies dealing with the electrochemical durability of N-doped carbons are carried out for the $\mathrm{N}$-doped graphitized structures, such as $\mathrm{N}-\mathrm{CNs}$ [17] or N-doped graphene [38], and correlate the superior stability with the presence of substantial amount of quaternary and graphitic N-C structures (Fig. 1 insert). The electrochemical stability for the polypyrrole-derived $\mathrm{N}$-doped carbon was recently reported [21] with emphasis on the type of carbon precursor (notice: an amorphous carbon black and graphitized tubes were used as carbon precursor, not like in our case, where PPy was the only $\mathrm{N}$ and $\mathrm{C}$ source). This study revealed that the electrochemical instability of PPy-derived $\mathrm{N}$-doped $\mathrm{C}$ is correlated with structural changes of amorphous phase-for comparison, the sample derived from the commercial graphitized structures remains stable. Thus, our goal was to correlate the effect of polymer precursor adapted for the synthesis of $\mathrm{N}$-doped carbon with a long-term durability over a commercially pertinent potential window. The electrochemical degradation was conducted in $\mathrm{O}_{2}$-saturated $0.1 \mathrm{M} \mathrm{KOH}$ by scanning potential (at least $2,000 \mathrm{CV}$ cycles) and

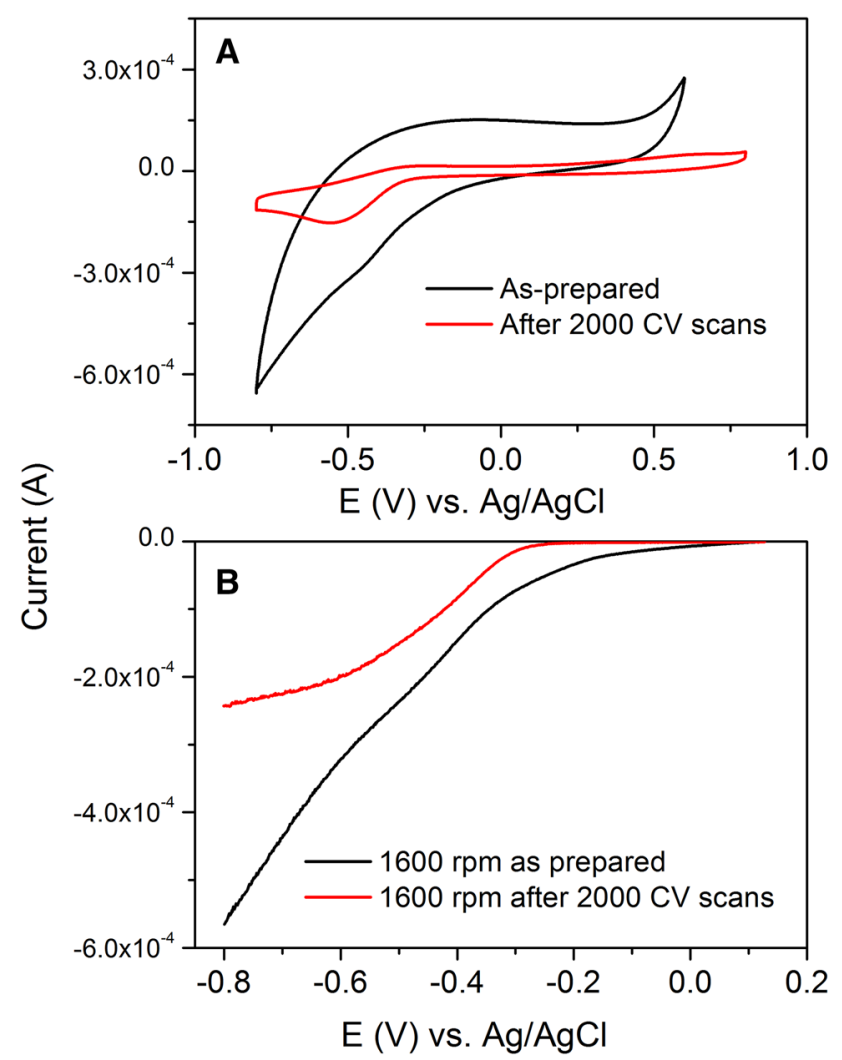

Fig. $3 \mathrm{CV}$ (a) and LSV at 1,600 rpm (b) of fresh-prepared (black) and after degradation (red) in $\mathrm{O}_{2}$-saturated $0.1 \mathrm{M} \mathrm{KOH}$ on glassy carbon disk electrode 
comparing CV and LSV of the ORR process (Fig. 3) for the freshly prepared electrode and after accelerated durability test. Figure 3 demonstrates that the sample synthesized in this work is not stable under cathode conditions. The electrochemical features, including redox activity and double-layer capacitance of porous carbon are much weaker after degradation test, regardless the amount of Nafion binder used for the electrode stability (Fig. $4 a, b$ correspond to the catalyst layer with doubled Nafion content performed with the goal of making mechanically stronger electrode). From the LSV (Fig. 3b), the current at $-0.45 \mathrm{~V}$ for the fresh electrode drops for about $38 \%$ after 2,000 cycles, which is significant loss when compared to previous reports [36]. Since there is a lack of standardized protocol of the durability test for the alkaline ORR catalyst as well as a lack of reliable information with regards to the stability of polypyrrole-derived $\mathrm{N}$-doped carbon we can conclude that the rapid electrochemical degradation of our materials originates from the low content of graphitized carbon and from the minor amount of graphitic N-C structures. With respect to the degradation test experimental conditions, we observe that the sample was unstable regardless the speed of potential scanning (data not shown) and the choice of the potential range in our work was the most relevant to operating conductions of the ORR cathode in alkali. The N-doped C layer casted on a porous $\mathrm{Ni}$ mesh also revealed significant instability (Fig. 4c, d), which indicates that the roughness of the electrode substrate and a potential risk of the catalyst layer delamination is not an issue here (as suggested by some groups [37]). With respect to the degradation test of $\mathrm{N}$-doped carbon on $\mathrm{Ni}$, we did not account the possible $\mathrm{Ni}$ activity toward ORR since there is no evidence of ORR catalysis on metallic $\mathrm{Ni}$ (please note we did not observe any resposne from $\mathrm{Ni}$ and the Ni substrate was fully covered by $\mathrm{N}$-doped $\mathrm{C}$ and Nafion binder-that minimized the contact of Ni metal with electrolyte). The test of electrochemical durability on $\mathrm{Ni}$ was carried out in order to exclude the effect of electrode substrate roughness on the detachment (physical destruction) of the $\mathrm{N}$-doped $\mathrm{C}$ layer.

Effect of carbon graphitization on electrochemical stability

XRD of different specimens was recorded in order to compare the crystalline structure of the $\mathrm{N}$-doped carbon [commercial control materials: Vulcan XC-72R carbon black and single walled carbon nanotubes (SWCNs) are
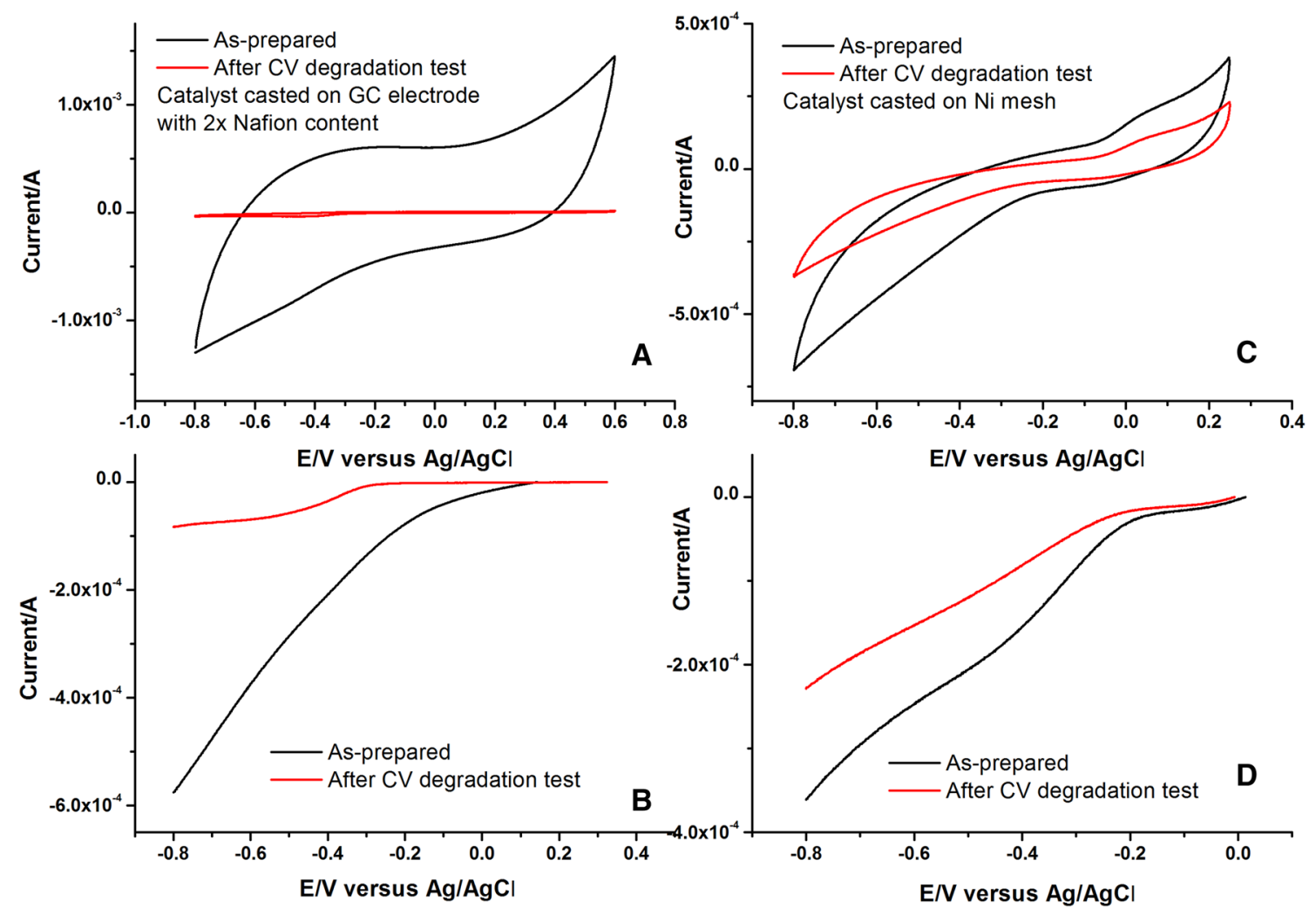

Fig. $4 \mathrm{CV}$ (a) and LSV at 1,600 rpm (b) of fresh-prepared (black) and after degradation (red) in $\mathrm{O}_{2}$-saturated $0.1 \mathrm{M} \mathrm{KOH}$ on glassy carbon disk electrode for the catalyst layer with doubled amount of
Nafion binder and CV (c) and LSV (d) on catalyst casted on rough $\mathrm{Ni}$ mesh with standard Nafion content 
used as references of amorphous and crystalline structures]. This structural investigation reveals the level of crystallization, since there is a potential risk that the amorphous carbon (that is less resistant to the corrosion) collapses during the electrochemical cycling [39]. The diffraction profiles of all carbons (Fig. S5) show the presence of an asymmetric band around $\sim 25.5^{\circ}$ also designated to the (002) plane and is associated with the spacing of aromatic ring layer of the graphite-like structures (crystalline carbon), and a weaker at $\sim 42.3^{\circ}$ of the (101) plane also denoted as a "10 peak" corresponding to the two-dimensional orientation of graphene planes [40, 42]). The major difference is observed between the symmetry of (002) and the intensity of " 10 peak" for the $\mathrm{N}$-doped $\mathrm{C}$ and a commercial carbon black (Vulcan XC-72R) when compared to SWCNs, indicating that first two samples have intermediate structures between graphite and amorphous state called turbostratic structure or random layer lattice structure. The "10 peak" at $43.5^{\circ}$ of the SWCNs is stronger in comparison to other carbons, signifying a higher degree of crystallinity. Also, in the case of SWCNs asymmetric (002) band at $\sim 25.5^{\circ}$ showed an additional peak shifted toward lower angle $\left(\sim 20^{\circ}\right)$ called $\gamma$ band and is attributed to the presence of saturated structures such aliphatic side chains that are attached to the edge of crystallites [41]. This $\gamma$ shoulder reflects the packing distance of saturated structures (however is not a direct indication on higher crystalline phase of the SWCNs). XRD analysis is further correlated with the XPS studies (Fig. 5) of the degraded $\mathrm{N}$-doped carbon and the proposed mechanism of degradation of $\mathrm{C}-\mathrm{C}$ and $\mathrm{N}-\mathrm{C}$ bonds.

The $\mathrm{C} 1 \mathrm{~s}$ core level peak (Fig. 5a) can be resolved into four components with maxima at 284.9, 286.2, 288.4 and $289.7 \mathrm{eV}$, representing $s p^{2} \mathrm{C}-s p^{2} \mathrm{C}$ graphite bonds, $\mathrm{N}-s p^{2} \mathrm{C}$ ( $\mathrm{N}$ substitution in graphite-like configuration), $\mathrm{C}-\mathrm{O}$ and $\mathrm{C}=\mathrm{O}$ functionalities and $\mathrm{N}-s p^{3} \mathrm{C}$ (pyrrolic), respectively [43-45]. Also, a small peak at $292.5 \mathrm{eV}$ of the $\mathrm{C}_{-} \mathrm{F}_{2}$ bonding is localized and associated with Nafion binder [46] and the intensity of C-F peaks for the fresh and degraded samples depends on the effectiveness of the washing step and do not affect the $\mathrm{C}-\mathrm{C}, \mathrm{C}-\mathrm{O}$ and the $\mathrm{C}-\mathrm{N}$ signals. Furthermore, the $\mathrm{C} 1 \mathrm{~s}$ narrow scan of the fresh and degraded sample revealed strikingly different distribution of carbon chemical states (Fig. 5c). The graphitic carbon disappeared completely for both $\mathrm{C}-\mathrm{C}$ and $\mathrm{N}-\mathrm{C}$ contributions, the signal of $\mathrm{C}-\mathrm{O}, \mathrm{C}=\mathrm{O}$ and indicating opening of aromatic ring [47] increased dramatically and the presence of pyrrolic $\mathrm{N}-s p^{3} \mathrm{C}$ bonds is no longer obvious. This clearly indicates on irreversible degradation of the whole carbon network, including breaking of the strongest graphitic $\mathrm{C}-\mathrm{C}$ and $\mathrm{C}-\mathrm{N}$ bonds. This is further complemented by the analysis of $\mathrm{N} 1 \mathrm{~s}$ core level spectrum (Fig. 5b, d). The narrow scan of $\mathrm{N} 1 \mathrm{~s}$ of the fresh $\mathrm{N}$-doped carbon (Fig. $5 \mathrm{~b}$ ) containing all $\mathrm{N}-\mathrm{C}$ components (graphitic, pyrrolic, pyridinic, and quaternary-as discussed in detail in conjunction with Fig. 1), changed significantly after the degradation (Fig. 5d). All signals assigned to the $\mathrm{N}-\mathrm{C}$ functionalities of $\mathrm{N}$-doped $\mathrm{C}$ disappeared, similar to the $\mathrm{C}-\mathrm{N}$ bonds in Fig. 5a. Taken together, this clearly demonstrates that the chemical structure of material changed during the accelerated degradation test. The signal assigned to the open form of $\mathrm{N}-\mathrm{C}$ pyrrolic ring at $401.7 \mathrm{eV}$ [47], and new signals at $402.7 \mathrm{eV}$ corresponding to $-\mathrm{C}=\mathrm{N}-\mathrm{OH}$, at $403.8 \mathrm{eV}$ assigned to $-\mathrm{C}-\mathrm{N}=\mathrm{O}$ group can be identified $[43,48,49]$. The analysis of both $\mathrm{C}$ and $\mathrm{N} 1 \mathrm{~s}$ core signals before and after degradation confirmed irreversible changes in the carbon structure.

Effect of chemical composition of N-doped carbon: role of polypyrrole precursor: proposed mechanisms for the degradation of $\mathrm{N}$-doped carbon

Scheme 1 represents possible reaction paths of the polypyrrole-derived $\mathrm{N}$-doped carbon. The steps 1-5 correspond to the ORR process on $\mathrm{N}-\mathrm{C}$ active centers that proceeds through reversible ring opening-cleavage route [7], and secondary degradation mechanism following steps 6-16. Regardless the electrochemical oxidation of carbon due to the massive amount of amorphous phase, especially for the most outer carbon planes (Fig. $5 \mathrm{c}$; $\mathrm{C}-\mathrm{O}$ functionalities are predominant structures), more complex degradation mechanism related to the $\mathrm{N}$-graphitic active sites should be taken into account. In the first step (1) the appropriate double bonds rearrangements are the driving force for the primary attack on the triplet oxygen atom. The high activation energy of kinetically unfavorable structure (3) is overcome at higher operating temperature, which lowers the barrier of Gibb's free energy required for this reaction to proceed. The electrochemically driven homolytic cleavage of the peroxy bond (3), which spontaneously forms an aldehyde group (5) can be considered. Furthermore, an unpaired electron in the pyridinic ring together with the hydroxyl radical anion will form a radical 6-exotrig ring closure (classified according to Baldwin rules), generating the molecular pattern (6-7). Under an oxidizing potential, the free electron pair of nitrogen attacks an adjacent carbon atom, leading to the peroxy group (7 and 10). The unfavorable molecule (11) can further react with hydroxyl radical anion generated in the reaction mixture through the electrochemically driven homolytic cleavage and create structure (12). The latest may react with hydrogen peroxide (by-product of 2-electron ORR process [29-31]) and form N-oxide (13-16). Furthermore, we speculate that the structure (5) instead of recovering to step (4), is modified under attack of a strong oxidizing agent, $\mathrm{H}_{2} \mathrm{O}_{2}$ [29-31], generating products (8-9) in Scheme 1. The

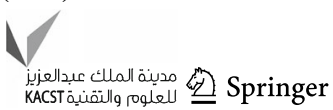




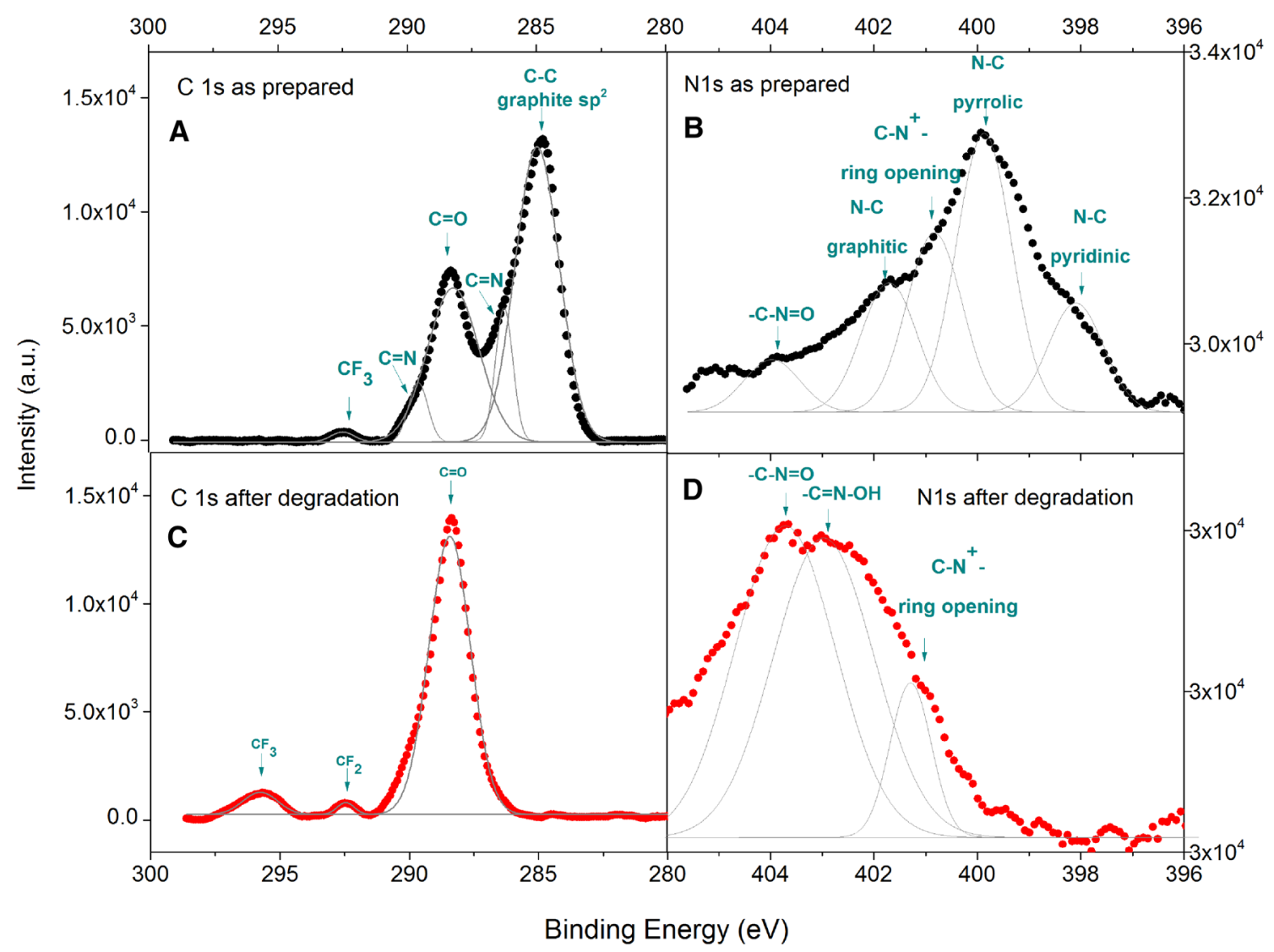

Fig. 5 XPS narrow scans of the C 1s (a, c) and N 1s (b, d) signals before (black) and after electrochemical durability test (red)

structure (9) we consider as a very active for oxygen reduction based on similarity the hydroquinone structure, thus may react in the same pattern as anthraquinone in the industrial production of hydrogen peroxide [50]. Under reducing conditions the step 5 in Scheme 1 will recover to the initial graphitic state of 1 , which is a well-known path for the ORR on $\mathrm{N}-\mathrm{C}$ graphitic sites [7]. There is also possibility of a side reaction (another degradation path) called Dakin reaction, which takes place on the aldehyde's formyl group (Scheme 2). The attack of the free electron pair of hydrogen peroxide will be favored under basic conditions, which forms a bicyclic molecule, pyrido[1,2-b] $[1,2]$ oxazine (Scheme 2, B4). Since XPS analysis identified nitroso and oxime functionalities in the degraded sample, we speculate that they are generated via steps $\mathrm{C} 1-$ $\mathrm{C} 3$ in Scheme 3 (C1 is formed by the reaction of $\mathrm{B} 1$ or 5 with hydrogen peroxide). Meanwhile the $-\mathrm{C}=\mathrm{N}-\mathrm{OH}$ and $\mathrm{C}-\mathrm{N}=\mathrm{O}$ groups produced during degradation of the pyrrolic nitrogen (predominant in our sample) might have also significant contribution (degradation mechanism not included). In summary, we observe that the degradation of $\mathrm{N}$-doped carbon is related to an excess of pyrrolic and pyridinic nitrogen in our product. The oxidation of pyridinic nitrogen is correlated with the weakening or breaking
$\mathrm{C}-\mathrm{C}$ bonds presumably from the less crystalline phase. Based on our observations, we propose that the electrochemically stable $\mathrm{N}$-doped carbons should possess quaternary (or graphitic) nitrogen as the main structure in crystalline carbon network. In addition, the polymer precursor should deliver stable, preferably aromatic carbon structures, for this reason other precursors (e.g., polyaniline), should generate more electrochemically stable $\mathrm{N}$-doped carbons, and will be the subject of our future study.

\section{Conclusion}

In this work we validate the electrochemical stability of polypyrrole-derived $\mathrm{N}$-doped carbon, by generating a model compound that is comparable to the current state-ofthe-art doped carbon with porous structure and a nitrogen doping level of 3-4 at.\%, consisting of $56 \%$ pyrrolic N, $36.1 \%$ pyridinic $\mathrm{N}$ and only $\sim 8 \%$ graphitic $\mathrm{N}$ centers. Although, the electrochemical studies show that N-doped carbon can catalyze ORR in alkaline electrolyte via a favorable four-electron pathway, the long-term electrochemical stability of this material is very poor comparing 


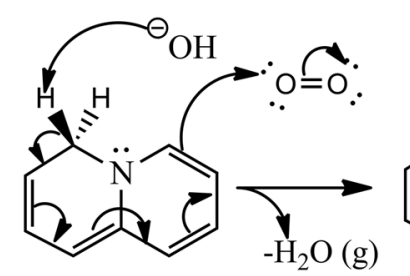

(1)<smiles>CC(=O)C1C=CC=C2C=CC=CN2C1</smiles>

(5)

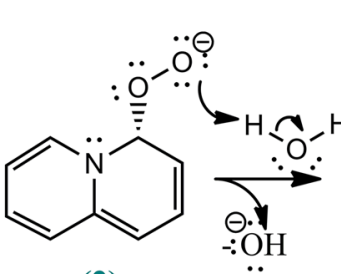

(2)<smiles>CCO[C@H](COC)[C@H]1C=CC=C2C=CC=CN21</smiles>

(3)<smiles>O=C(O)c1cccc2cccc(=O)n12</smiles>

(4)<smiles>O=C(c1ccccc1)N1CCCC1</smiles>

(6)

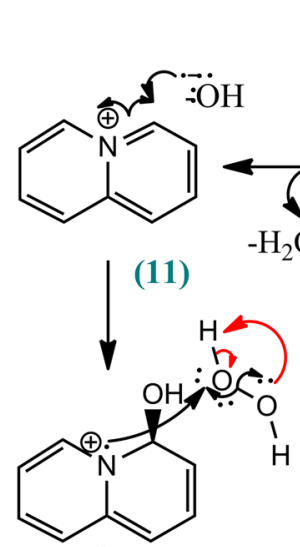

(12)

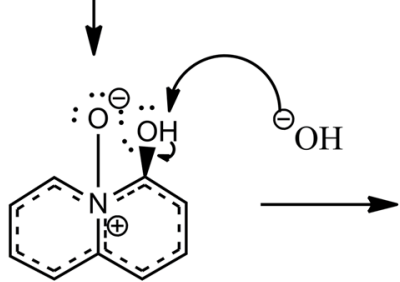

(13)

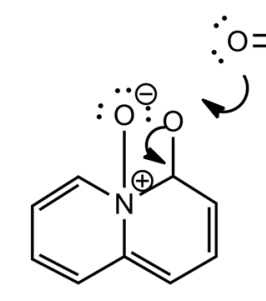

(14)
(7)<smiles>O=C(O)C1C=CC=C2C=CC=CN21</smiles><smiles>CC(C)C(=O)O[Na]</smiles><smiles>[3H][13CH3]</smiles><smiles>[O-][N+]12C=CC=CC1C=CC=C2</smiles>

(9)

Scheme 1 Oxygen evaluation on N-C active center during ORR through ring opening-to-cleavage (steps 1-5) and irreversible degradation mechanism of $\mathrm{N}$-doped carbon (steps 6-16)

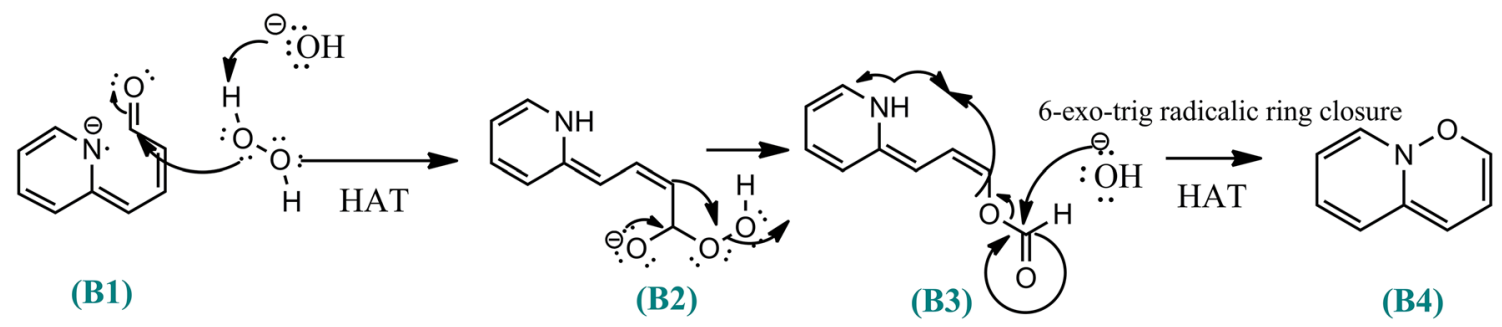

Scheme 2 Dakin-West mechanism with hydrogen atom transfer (HAT) from the solvent and hydrogen peroxide

to $\mathrm{N}$-doped $\mathrm{CNs}$ or $\mathrm{N}$-doped graphene. There are two reasons for the electrochemical instability, first is a very low content of graphitized carbon in comparison to commercial carbon black or SWCNs. Second, is a low content of graphitic nitrogen (only 8 at.\%), which is the most electronically and chemically stable structure in this 
Scheme 3 The formation of nitroso and oxime groups during electrochemical degradation of $\mathrm{N}$-doped C

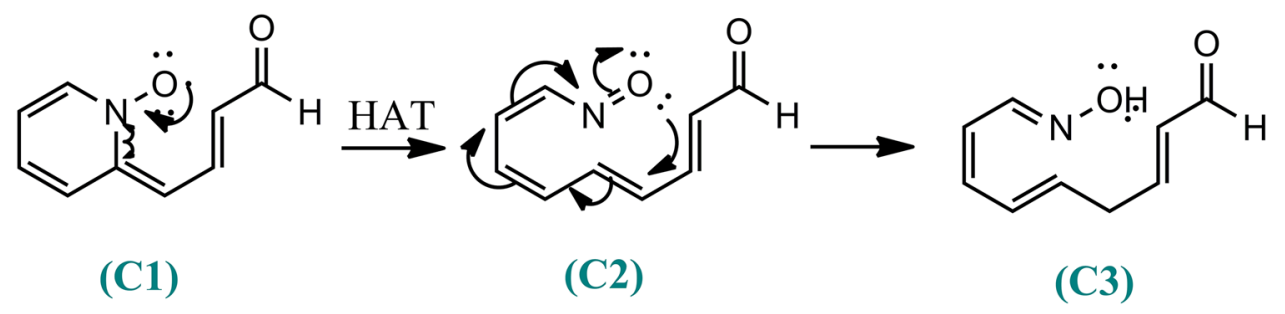

absorption spectroscopic study. J. Phys. Chem. C 118, 7765-7771 (2014)

type of materials. Furthermore, the XPS analysis of degraded samples revealed that both $\mathrm{C}-\mathrm{C}$ and $\mathrm{N}-\mathrm{C}$ bonds are broken and massive amount of oxygen containing functionalities are generated on carbon and nitrogen centers after long-term electrochemical durability test, based on the surface analysis we proposed several degradation paths. This irreversible oxidation is correlated with the presence of significant content or pyrrolic and pyridinic $\mathrm{N}$ close to the edge of the carbon network. These are generated by the polypyrrole precursor. Although $\mathrm{N}$ as n-type dopant stabilizes aromatic rings, giving high electrochemical stability for the graphitic and quaternary nitrogen centers, these are minor structures in our material, consequently, the polypyrrole-derived carbon is less stable under oxidizing potential. As a solution, a careful selection of the polymer precursor has to be carried out in order to create highly graphitic carbon with nitrogen in quaternary (or graphitic) states. These studies critically revised the influence of polymer precursor on the electrochemical stability of the resulting $\mathrm{N}$-doped carbon materials, closing the knowledge gap with respect to their long-term durability under oxidizing potential.

Acknowledgments We thank you Carl-Zeiss Foundation for financial support.

Open Access This article is distributed under the terms of the Creative Commons Attribution License which permits any use, distribution, and reproduction in any medium, provided the original author(s) and the source are credited.

\section{References}

1. Wang, H., Maiyalagan, T., Wang, X.: Review on recent progress in nitrogen-doped graphene: synthesis, characterization, and its potential applications. ACS Catal. 2(5), 781-794 (2012)

2. Han, J., Xu, G., Ding, B., Pan, J., Dou, H., MacFarlane, D.R.: Porous nitrogen-doped hollow carbon spheres derived from polyaniline for high performance supercapacitors. J. Mater. Chem. A 2, 5352-5357 (2014)

3. Li, X.H., Antonietti, M.: Metal nanoparticles at mesoporous $\mathrm{N}$-doped carbons and carbon nitrides: functional Mott-Schottky heterojunctions for catalysis. Chem. Soc. Rev. 42, 6593-6604 (2013)

4. Zhu, P., Song, J., Lu, D., Wang, D., Jaye, C., Fischer, D.A., Wu, T., Chen, Y.: Mechanism of enhanced carbon cathode performance by nitrogen doping in lithium-sulphur battery: an X-ray
5. Sevilla, M., Yu, L., Fellinger, T.P., Fuertesa, A.B., Titiricic, M.M.: Polypyrrole-derived mesoporous nitrogen-doped carbons with intrinsic catalytic activity in the oxygen reduction reaction.

6. Gong, K., Du, F., Xia, Z., Durstock, M., Dai, L.: Nitrogen-doped carbon nanotube arrays with high electrocatalytic activity for oxygen reduction. Science 323, 760-764 (2009)

7. Kim, H., Lee, K., Woo, S.I., Jung, Y.: On the mechanism of enhanced oxygen reduction reaction in nitrogen-doped graphene nanoribbons. Phys. Chem. Chem. Phys. 13, 17505-17510 (2011)

8. Liu, S., Tian, J., Wang, L., Zhang, Y., Luo, Y., Asiri, A.M., AlYoubi, A.O., Sun, X.: A novel acid-driven, microwave-assisted, one-pot strategy toward rapid production of graphitic N-doped carbon nanoparticles-decorated carbon flakes from $\mathrm{N}, \mathrm{N}$ dimethylformamide and their application in removal of dye from water. RSC Adv. 2, 4632-4635 (2012)

9. Geng, D., Chen, Y., Chen, Y., Li, Y., Li, R., Sun, X., Ye, S., Knights, S.: High oxygen-reduction activity and durability of nitrogen-doped graphene. Energy Environ. Sci. 4, 760-764 (2011)

10. Zhang, Y., Fugane, K., Mori, T., Niu, L., Ye, J.: Wet chemical synthesis of nitrogen-doped graphene towards oxygen reduction electrocatalysts without high-temperature pyrolysis. J. Mater. Chem. 22, 6575-6580 (2012)

11. Wang, Y., Shao, Y., Matson, D.W., Li, J., Lin, Y.: Nitrogendoped graphene and its application in electrochemical biosensing.

12. Liu, Z., Zhang, X., Poyraz, S., Surwade, S.P., Manohar, S.K.: Oxidative template for conducting polymer nanoclips. J. Am. Chem. Soc. 132, 13158-13159 (2010)

13. Cao, C., Zhuang, X., Su, Y., Zhang, Y., Zhang, F., Wu, D., Feng, X.: 2D Polyacrylonitrile brush derived nitrogen-doped carbon nanosheets for high-performance electrocatalysts in oxygen reduction reaction. Polym. Chem. 5, 2057-2064 (2014)

14. Geng, D., Liu, H., Chena, Y., Li, R., Sun, X., Ye, S., Knights, S.: Non-noble metal oxygen reduction electrocatalysts based on carbon nanotubes with controlled nitrogen contents. J. Power Sour. 196, 1795-1801 (2011)

15. Liu, D., Zhang, X., Sun, Z., You, T.: Free-standing nitrogendoped carbon nanofiber films as highly efficient electrocatalysts for oxygen reduction. Nanoscale 5, 9528-9531 (2013)

16. Liu, J., Sasaki, K., Lyth, S.M.: Electrochemical oxygen reduction on metal-free nitrogen-doped graphene foam in acidic media. ECS Trans. 58(1), 1529-1540 (2013)

17. Li, H., Liu, H., Jong, Z., Qu, W., Geng, D., Sun, X., Wang, H.: Nitrogen-doped carbon nanotubes with high activity for oxygen reduction in alkaline media. Int. J. Hydrogen Energy 36, 2258-2265 (2011)

18. Qu, L., Liu, Y., Baek, J.B., Dai, L.: Nitrogen-doped graphene as efficient metal-free electrocatalyst for oxygen reduction in fuel cells. ACS Nano. 4, 1321-1326 (2010)

19. Stevens, D.A., Hicks, M.T., Haugen, G.M., Dahn, J.R.: Ex situ and in situ stability studies of PEMFC catalysts: effect of carbon RSC Adv. 3, 9904-9910 (2013) ACS Nano. 4, 1790-1798 (2010) 
type and humidification on degradation of the carbon. J. Electrochem. Soc. 152, A2309-A2315 (2005)

20. Li, Y.S., Zhao, T.S., Liang, Z.X.: Effect of polymer binders in anode catalyst layer on performance of alkaline direct ethanol fuel cells. J. Power Sour. 190, 223-229 (2009)

21. Zhao, A., Masa, J., Muhler, M., Schuhmann, W., Xia, W.: $\mathrm{N}$-doped carbon synthesized from $\mathrm{N}$-containing polymers as metal-free catalysts for the oxygen reduction under alkaline conditions. Electrochim. Acta 98, 139-145 (2013)

22. Chougulea, M.A., Pawara, S.G., Godse, P.R., Mulik, R.N., Sen, S., Patila, V.B.: Synthesis and characterization of polypyrrole (PPy) thin films. Soft Nanosci. Lett. 1, 6-10 (2011)

23. Lee, K.R., Lee, K.U., Lee, J.W., Ahn, B.T., Woo, S.I.: Electrochemical oxygen reduction on nitrogen doped graphene sheets in acid media. Electrochem. Commun. 12, 1052-1055 (2010)

24. Subramanian, N.P., Li, X., Nallathambi, V., Kumaraguru, S.P., Colon-Mercado, H., Wu, G., Lee, J.W., Popov, B.N.: Nitrogenmodified carbon-based catalysts for oxygen reduction reaction in polymer electrolyte membrane fuel cells. J. Power Sour. 188, 38-44 (2009)

25. Luo, Z., Lim, S., Tian, Z., Shang, J., Lai, L., MacDonald, B., Fu, C., Shen, Z., Yu, T., Lin, J.: Pyridinic N doped graphene: synthesis, electronic structure, and electrocatalytic property. J. Mater. Chem. 21, 8038-8044 (2011)

26. Niwa, H., Horiba, K., Harada, Y., Oshima, M., Ikeda, T., Terakura, K., Ozaki, J., Miyata, S.: X-ray absorption analysis of nitrogen contribution to oxygen reduction reaction in carbon alloy cathode catalysts for polymer electrolyte fuel cells. J. Power Sources 187, 93-97 (2009)

27. Brun, N., Wohlgemuth, S.A., Osiceanub, P., Titiricic, M.M.: Original design of nitrogen-doped carbon aerogels from sustainable precursors: application as metal-free oxygen reduction catalysts. Green Chem. 15, 2514-2524 (2013)

28. Liu, H., Cao, Y., Wang, F., Huang, Y.: Nitrogen-doped hierarchical lamellar porous carbon synthesized from the fish scale as support material for platinum nanoparticle electrocatalyst toward the oxygen reduction reaction. ACS Appl. Mater. Interfaces 6(2), 819-825 (2014)

29. Jin, Z., Nie, H., Yang, Z., Zhang, J., Liu, Z., Xu, X., Huang, S.: Metal-free selenium doped carbon nanotube/graphene networks as a synergistically improved cathode catalyst for oxygen reduction reaction. Nanoscale 4, 6455-6460 (2012)

30. Zhang J (ed.) PEM Fuel Cell Electrocatalysts and Catalyst Layers: Fundamentals and Applications. Springer, New York, pp. 102 (2008)

31. Chen, Z., Higgins, D., Chen, Z.: Nitrogen doped carbon nanotubes and their impact on the oxygen reduction reaction in fuel cells. Carbon 48, 3057-3065 (2010)

32. Sidik, R.A., Anderson, A.B., Subramanian, N.P., Kumaraguru, S.P., Popov, B.N.: $\mathrm{O}_{2}$ reduction on graphite and nitrogen-doped graphite: experiment and theory. J. Phys. Chem. B 110, 1787-1793 (2006)

33. Shao, Y., Zhang, S., Engelhard, M.H., Li, G., Shao, G., Wang, Y., Liu, J., Aksay, I.A., Lin, Y.: Nitrogen-doped graphene and its electrochemical applications. J. Mater. Chem. 20, 7491-7496 (2010)
34. Liu, H., Zhang, Y., Li, R., Sun, X., Abou-Rachid, H.: Thermal and chemical durability of nitrogen-doped carbon nanotubes. J. Nanopart. Res. 14, 1016 (2-8) (2012)

35. Gang, W., More, K.L., Johnston, C.M., Zelenay, P.: High-performance electrocatalysts for oxygen reduction derived from polyaniline, iron, and cobalt. Science 332, 443-447 (2011)

36. Feng, L., Yang, L., Huang, Z., Luo, J., Li, M., Wang, D.: Enhancing electrocatalytic oxygen reduction on nitrogen-doped graphene by active sites implantation. Sci. Rep. 3-3306, 1-8 (2013)

37. Zhao, Y., Nakamura, R., Kamiya, K., Nakanishi, S., Hashimoto, K.: Nitrogen-doped carbon nanomaterials as non-metal electrocatalysts for water oxidation. Nat. Commun. 4, 1-4 (2013)

38. Peng, H., Mo, Z., Liao, S., Liang, H., Yang, L., Luo, F., Song, H., Zhong, Y., Zhang, B.: High performance Fe- and N- doped carbon catalyst with graphene structure for oxygen reduction. Sci. Rep. 3-1765, 1-7 (2013)

39. Ignaszak, A., Song, C., Zhu, W., Wang, Y., Zhang, J., Bauer, A., Baker, R., Neburchilov, V., Ye, S., Campbell, S.: Carbon$\mathrm{Nb}_{0.07} \mathrm{Ti}_{0.93} \mathrm{O}_{2}$ composite supported Pt-Pd electrocatalysts for PEM fuel cell oxygen reduction reaction. Electrochim. Acta 75, 220-228 (2012)

40. Saikia, B.K., Boruah, R.K., Gogoi, P.K.: A X-ray diffraction analysis on graphene layers of Assam coal. J. Chem. Sci. 121, 103-106 (2009)

41. Manoj, B., Kunjomana, A.G.: Study of stacking structure of amorphous carbon by X-ray diffraction technique. Int. J. Electrochem. Sci. 7, 3127-3134 (2012)

42. Hussain, R., Quadeer, R., Ahmad, M., Salem, M.: X-ray diffraction study of heat-treated graphitized and ungraphitized carbon. Turk. J. Chem. 24, 177-183 (2000)

43. Lim, S.H., Elim, H.I., Gao, X.Y., Wee, A., Ji, W., Lee, J.Y., Lin, J.: Electronic and optical properties of nitrogen-doped multiwalled carbon nanotubes. Phys. Rev. B 73, 045402-1 (2006)

44. Chao, S., Lu, Z., Bai, Z., Cui, Q., Qiao, J., Yang, Z., Yang, L.: Tuning synthesis of highly active nitrogen-doped graphite and determining the optimal structure from first-principles calculations. Int. J. Electrochem. Sci. 8, 8786-8799 (2013)

45. Nolan, H., Mendoza-Sanchez, B., Kumar, N.A., McEvoy, N., O’Brien, S., Nicolosi, V., Duesberg, G.S.: Nitrogen-doped reduced graphene oxide electrodes for electrochemical supercapacitors. Phys. Chem. Chem. Phys. 16, 2280-2284 (2014)

46. XPS database: http://xpssimplified.com

47. Allouche, J., Le Beulze, A., Dupin, J.C., Ledeuil, J.B., Blanc, S., Gonbeau, D.: Hybrid spiropyran-silica nanoparticles with a coreshell structure: sol-gel synthesis and photochromic properties. J. Mater. Chem. 20, 9370-9378 (2010)

48. Wilken, R., Holländer, A., Behnisch, J.: Surface radical analysis on plasma-treated polymers. Surf. Coat. Technol. 116-119, 991-995 (1999)

49. Wilken, R., Holländer, A., Behnisch, J.: Nitric oxide radical trapping analysis on vacuum-ultraviolet treated polymers. Macromolecules 31, 7613-7617 (1998)

50. Goor, G., Glenneberg, J., Jacobi, S.: "Hydrogen Peroxide". Ullmann's Encyclopedia of Industrial Chemistry. Wiley, Weinheim (2007) 